\title{
Possibility of using waste glass powder and ceramic tile as an aggregate on the flexural behavior and strength properties.
}

\author{
Amjad Ali K.Sharba \\ amjada.sharba@uomustansiriyah.edu.iq \\ * Dept. of Civil Engineering, Mustansiriya University, Iraq, Baghdad
}

\begin{abstract}
The study discusses the results of the experiment carried out about the effects of incorporation of waste ceramic tiles aggregate combined with waste glass powder on the performance of cementations mixtures. Crushed gravels in concrete mixes were replaced by ceramic tile (CT). Their ratios were $15 \%, 30 \%, 45 \%$, and60\%. On the other hand, glass powder was used to replace fine aggregate at a percentage of $15 \%, 30 \%$, and $45 \%$. Ten different forms of concrete incorporated waste ceramic and glass powder was designed and prepared. The mixtures were examined in their fresh and hardened states in terms of workability, density, compressive, tensile strength, and flexural beam tests. The water/binder ratios and cement content of all mixtures remain constant. The results pointed out that by applying waste glass powder in concrete mixture that contained waste ceramic tiles have enhancement the strength properties. Additionally, both waste materials are considered as a good potential for integrating them in the concrete mixture as compared to the conventional concrete. As a corollary, the best result was obtained with a mix containing $25 \%$ glass powder and $15 \%$ ceramic tile. These alternatives have many benefits environmentally, economically and show positive effects on the characteristics of concrete mixtures.
\end{abstract}

Keywords: waste ceramic tiles, glass powder, strength properties, sustainable development.

\section{Introduction}

Research on the deployment of modern technology in concrete production proves vital since concrete has long been used in the construction industry for more than two centuries. Yet, the most persisting problem encountered by engineering enterprise in all countries is the removal and reusability of the wastage. Large amounts of wastages are thrown away annually in many countries, especially in Iraq in which there is not a well-defined system of recycling such waste materials like ceramic tiles and glass powder. The advantage of recycling of the wastages is to convert it to aggregate and hence provide more landfill space in addition to decrease the demand for more natural raw materials [1]. Still, there is a problem related to the shortage of aggregate so the best solution is to utilize this type of waste material and in turn alleviating the environmental challenges [2]. Another solution to the environmental problem caused by throwing away the wastage is to replace CT and GP by the essential aggregate in normal concrete mixes [3, 4]. However, the recycling ratios of waste glass have gone up in many countries owing to the increasing extraction of natural sources. Anyway, some recycled glass fractions prove useless in manufacturing new glass productions because they are either contaminated or so small to satisfy manufacturing specifications. These glass fractions are better used as concrete ingredients including aggregates and supplementary cementitious material, due to potential property of amorphous glass to display pozzolanic reactivity $[5,6]$. Waste glass with such pozzolanic reactivity as a municipal waste has been extensively applied as supplementary cementitious materials and aggregate replacement [7-10]. [11, 12] also believe that due its smooth surface waste glass as aggregate in concrete cause an enhancement in the workability. Similarly, self-compacting waste glass aggregates were developed by some researches [13]. Material of high content of amorphous silica and sodium, alkali-silica reaction is an earnest challenge to use large size glass cullet in concrete [14]. However, the alkali-silica reaction could be hindered of fine pozzolanic materials such as metakolin and slag [15], and even glass powder as a fine material can be utilized to suppress the expansion [16,17,18]. The major aim of the research is to recognize the presence of the CT and GP in the concrete mixture in terms of strength characterizes as gravel and sand, respectively. The strength qualities examined are the behavior of the RC beam in terms of bending strength, tensile strength, compressive and flexural strength. 


\section{Material}

\subsection{Cement}

The cement employed in this investigation is 42.5 grade was supplied by Tasluja faculty, Iraq. The cement that collected from the manufactured was without lumps and consider as a binder and the cement has a specific gravity of 3.11. After performing the test toward setting time it exhibited that the initial and final setting time was 160 and 220 minutes, respectively. Table 1 presents the chemical properties of cement.

Table 1. Demonstrates the chemical analysis of the cement.

\begin{tabular}{lc}
\hline Compounds & \% (By weight) \\
\hline $\mathrm{Fe}_{2} \mathrm{O}_{3}$ & 3.42 \\
$\mathrm{Al}_{2} \mathrm{O}_{3}$ & 6.12 \\
$\mathrm{SiO}_{2}$ & 22.23 \\
$\mathrm{MgO}$ & 1.43 \\
$\mathrm{SO}_{3}$ & 2.31 \\
$\mathrm{CaO}$ & 63.96 \\
$\mathrm{Lime}$ saturation factor & 0.91 \\
Loss of ignition & 0.86 \\
Main compounds(Bogues equation) & \\
$\mathrm{C}_{3} \mathrm{~A}$ & 9.32 \\
$\mathrm{C}_{2} \mathrm{~S}$ & 22.40 \\
$\mathrm{C}_{3} \mathrm{~S}$ & 51.12 \\
$\mathrm{C}_{4} \mathrm{AF}$ & 10.91
\end{tabular}

\subsection{Fine aggregate}

The fine aggregate has sieved and it reveals that the sand conforms to zone II. It was taken from Al-Akhaidher region in Iraq with the highest size of $4.75 \mathrm{~mm}$ which complies with the specification that related to the gradation fine aggregate. The rate of water absorption is $1.43 \%$, the value of specific gravity, density, fineness modulus was 2.61 , $1676 \mathrm{~kg} / \mathrm{m} 3,2.57$. Table 2 exhibits the gradation of the sand.

Table 2. Particle size distributions of fine aggregate.

\begin{tabular}{lcc}
\hline Sieve size & $\begin{array}{c}\text { Accumulated percentage } \\
\text { passing }\end{array}$ & $\begin{array}{c}\text { Limit of I.Q.S. No 45/1984 } \\
\text { Zone (2) }\end{array}$ \\
\hline 4.75 & 97 & $90-100$ \\
2.36 & 86 & $75-100$ \\
1.18 & 76 & $55-90$ \\
0.6 & 61 & $35-90$ \\
0.3 & 21 & $8-30$ \\
0.15 & 5 & $0-10$
\end{tabular}




\subsection{Coarse aggregate}

Natural crushed stone aggregate adopted in this study from local sources and the particle size sieved and crossed through the sieve size $14 \mathrm{~mm}$, it was collected from the Al-Nibaey zone in Iraq. The bulk density of gravel was of $1567 \mathrm{~kg} / \mathrm{m}^{3}$.

\subsection{Water}

Potable water collected from the Laboratory available at the university and was used for preparing the mix concrete and also for curing the specimens. The water used was clean and did not include any contents of oil and acids.

\subsection{Waste Ceramic Tile}

The waste ground ceramic tiles applied in this research were collected from the sites of demolished buildings. To obey the specification of coarse aggregate the ground tiles were crushed into cracked pieces by using the jaw crusher. The ceramic tile preparation process is displayed in figure 1.

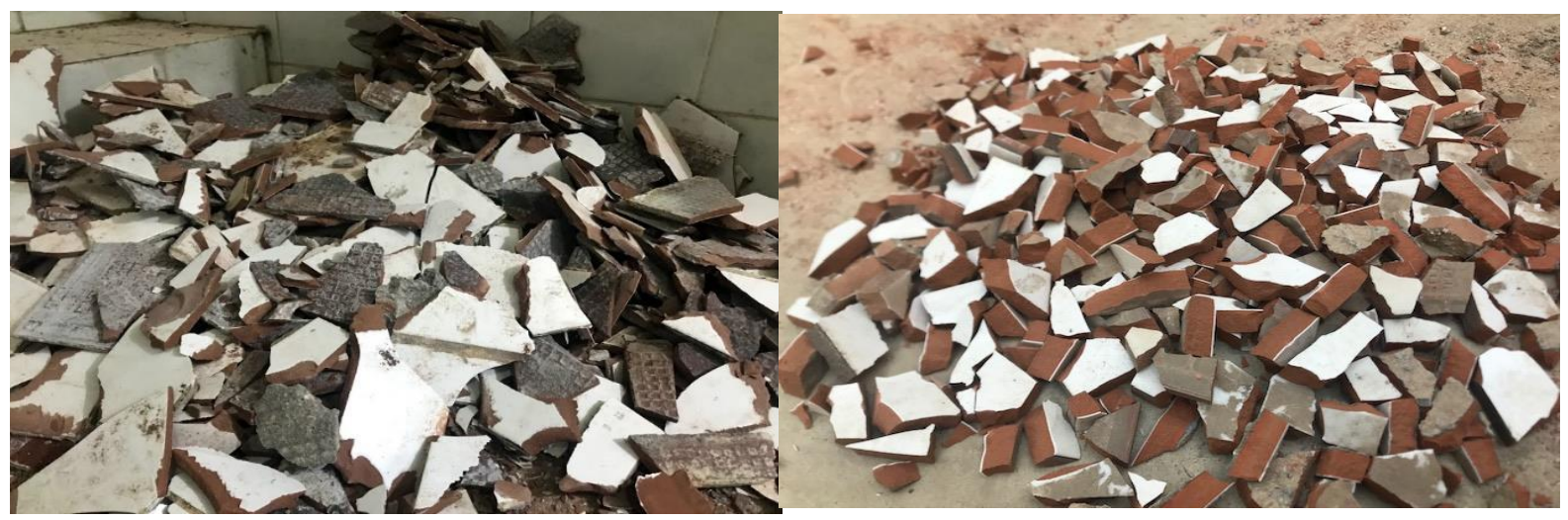

Fig. 1. The ground ceramic tile preparation process.

\subsection{Waste glass powder}

The glass powder is the consequence of the bottles made from glass that recovery in the landfill. During collect the bottles it selects only the same color, the waste glass in terms of physical properties is presented in table3. To follow the same gradation of the fine aggregate those waste glasses were cleaned and after the process of cleaning it was crushed and finely grounded. The chemical composites of waste powder are displayed in table 3 . Figure 2 shows the waste glass powder employed in this investigation.

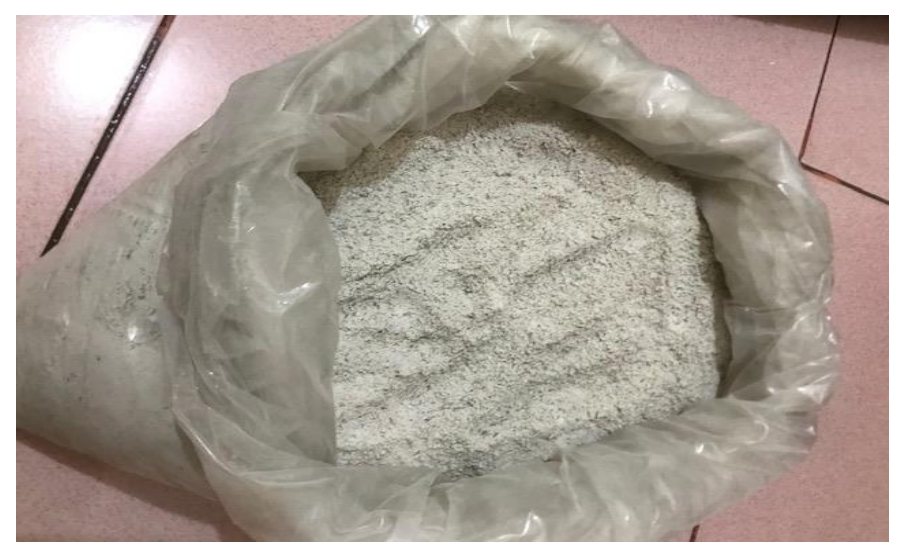


Fig.2 .Specimen of glass waste powder

Table 3. Physical properties and chemical composition of waste glass.

\begin{tabular}{lllc}
\hline Chemical content & $\%$ & Physical properties & $\%$ \\
\hline $\mathrm{Fe}_{2} \mathrm{O}_{3}$ & 1.24 & Color & Light gray \\
$\mathrm{CaO}$ & 7.67 & Finesse modulus & 2.31 \\
$\mathrm{Al}_{2} \mathrm{O}_{3}$ & 1.95 & Density kg/m & 1668 \\
$\mathrm{SiO}_{2}$ & 69.43 & Absorption & 0.41 \\
$\mathrm{SO}_{3}$ & 0.21 & Specific gravity & 2.17 \\
$\mathrm{MgO}$ & 6.85 & & \\
$\mathrm{Na}_{2} \mathrm{O}+\mathrm{K}_{2} \mathrm{O}$ & 8.96 & &
\end{tabular}

\section{Experimental procedure}

\subsection{Mixture proportioning}

Concrete mixes are comprised of three varieties that planned for this investigation. The conventional mixture, which consisted of gravel $(1015 \mathrm{~kg} / \mathrm{m} 3)$, sand $(695 \mathrm{~kg} / \mathrm{m} 3)$, cement $(390 \mathrm{~kg} / \mathrm{m} 3)$, and the water-concrete ratio of 0.49 . Another concrete mixture that contented waste ceramic tile was made of waste tile aggregate of $15 \%, 30 \%, 45 \%$, and $60 \%$ as a partial surrogate for coarse aggregate corresponding to the CT1, CT2, CT3, and CT4, respectively and with the alike amount of sand, cement, and water binder ratio. The last mixture includes glass powder was made as a partial substituted of sand as $15 \%, 25 \%$, and 35\%, corresponding to the GP1, GP2, and GP3, respectively and with the equivalent value of gravel, cement, and the ratio of water to cement. Whole varieties of concrete were considered for curing at 7,28 days.

\subsection{Preparation of specimens}

To prevent the adhesion of concrete in the mold, the molds were painted by mineral oil and also to make sure that the water during filling would not be escaped. Casting the concrete has been done by three layers of $50 \mathrm{~mm}$ each. For compacted each layer of the samples and reach the appropriate state, using the vibrating table for 1-1.5 min to avoid air bubbles revealed on the surface of the specimens. The concrete was removed after 24 hours to allow the sample to be dried and then directly immersed in freshwater until to reach the time of testing day.

\subsection{Testing of specimens}

1. The modes of casting, compaction, and curing were consistent with the specification of B.S1881:1952.

2. The Slump test was performed correspond to B.S1881, section 2.

3. Dry density: Cubes were been measured by selected from the curing water container before taking into consideration compression strength. The dry density comprises the average of four specimens of each mixture to calculate the value of dry density.

4. Compressive strength and tensile strength: cubes of concrete and cylinders were performed to agree with B.S.1881:1952. The cylinders and cubes that consider for split tensile and compressive strength were examined immediately after selecting from water storage. The mean value of split tensile and compressive strength was written for each mixture and age. 
5. Flexural strength and RC beam test: Prisms were implemented corresponding to ASTM C192-88, the RC beam samples were considered as a simply supported and examined under pure bending case. The capacity of the loading frame can reach a maximum load of 150 tones. Among $10 \mathrm{RC}$ beam specimens, 4 specimens were ceramic tile concrete and the other 3 were glass powder concrete, one for the reference concrete to make a comparison, and the last two samples were the combination between the two wastage (ceramic tile and glass powder). All the RC beams were in the same details of reinforcement as shown is figure 3 .

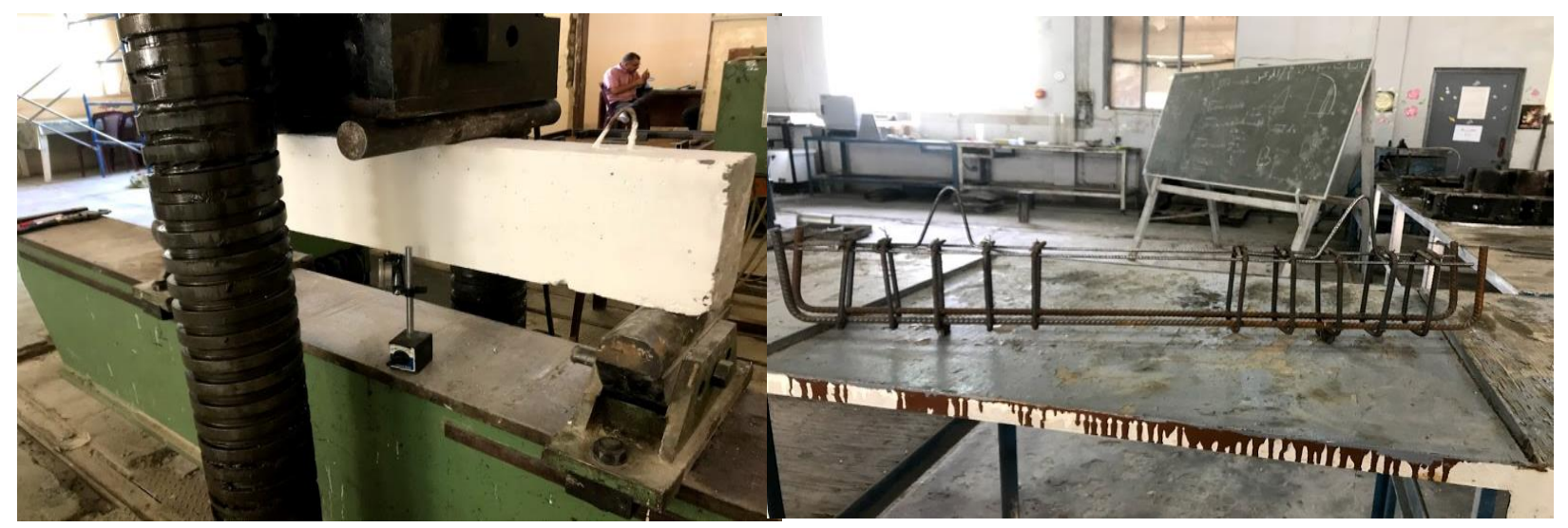

Fig. 3. Sample of RC beam

\section{Results and discussion}

The effects of the waste ceramic tile concrete mixture on the slump test have resulted in figure 4 . The outcomes point out that the amount of the workability is diminishing by raising the waste ceramic tile ratio. The decreases in the amount of slump value could be $16.17 \%, 26.47 \%, 35.2 \%$, and $42.6 \%$ for CT1, CT2, CT3, and CT4, respectively which can be attributed to more absorption of water by tile. On the other hand, substituted the fine aggregate with glass powder it indicates a decline in the value of slump as the waste glass ratio raised. The amount of reduction is $11.76 \%$, $17.65 \%$, and $25 \%$ for GP1, GP2, and GP3, respectively. This drop in the workability can be associated with the weak geometry of the glass waste, which gives a conclusion of lesser fluidity of the mixtures as well as the diminution of fineness modulus. [12] Notified that the amount of slump concrete has been decreased as the high ratio of glass waste increased. A study via [11] also declared that by raising the rate of glass powder as fine aggregate the workability of concrete would be decreased. Figure 4 represents the slump value of waste glass powder concrete. The lowest amount of slump revealed at CT4 represent $60 \%$ substitute coarse aggregate by waste ceramic tile.

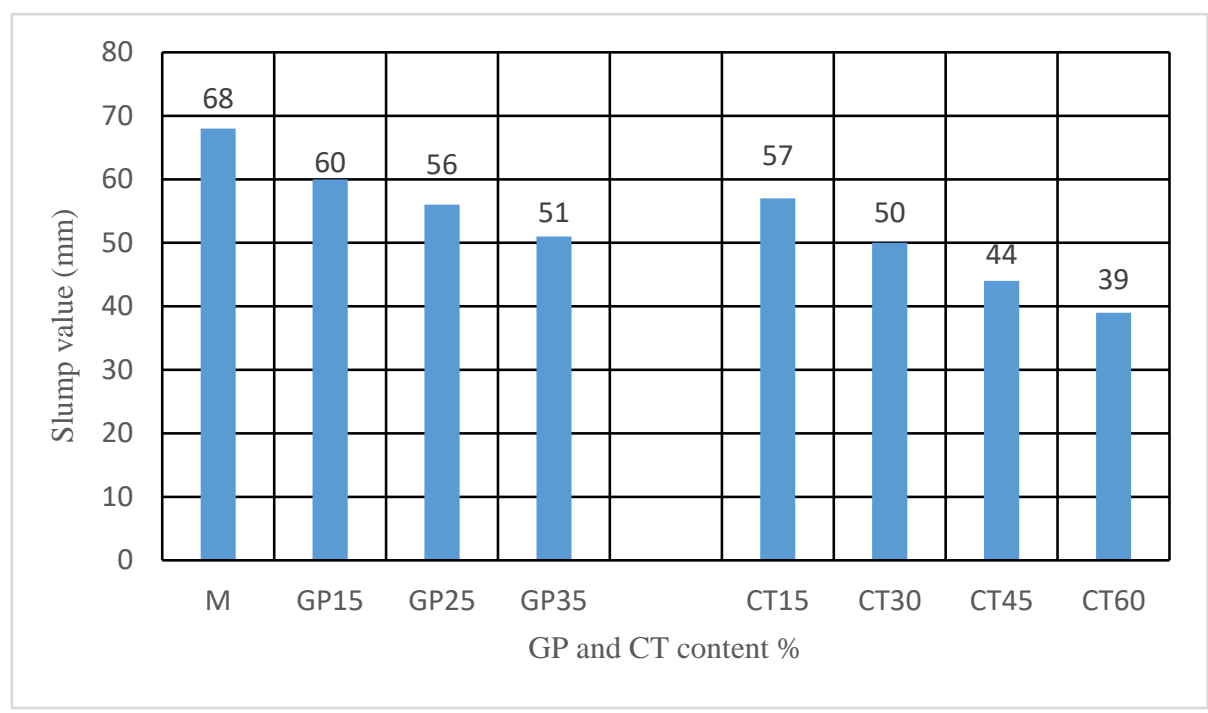


Fig. 4. Slump value of concrete that containing waste GP and CT.

\subsection{Density test}

The density of the concrete mixture that content waste ceramic tile concrete mixtures as represent CT1, CT2, CT3, and CT4 are shown in figure 5. The value of density tends to decline when the ratio of waste ceramic tile has been increased in each concrete mixture. The lowest density revealed at CT4 that contained $60 \%$ of ceramic tile as a replacement by coarse aggregate. As a result, by using wastage tile the overall weight of concrete will be reduced, it could be attributed to the unit weight of ceramic tile is lower than the coarse aggregate. By substitute, the fine aggregate to the waste glass the amount of density shows a reduction. Figure 6 displays the density of the concrete that includes waste glass after the age of curing reaches 28 days. Figure 7 describes the percentage of decline in the density of concrete mixture that incorporated waste glass powder. The same outcome was declared by [12], which verify that the unit weight of glass concrete mixture is lower from the one that didn't introduce waste glass.

Density of concrete containg ceramic tiles

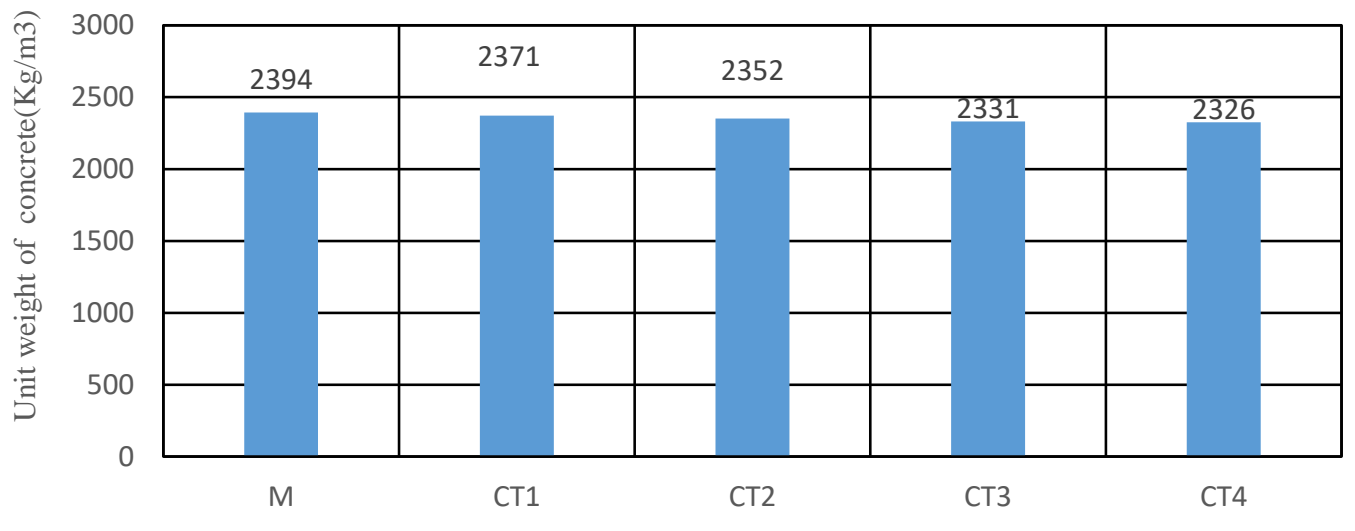

Fig. 5. Density of waste ceramic tile.

Density of concrete containg waste glass

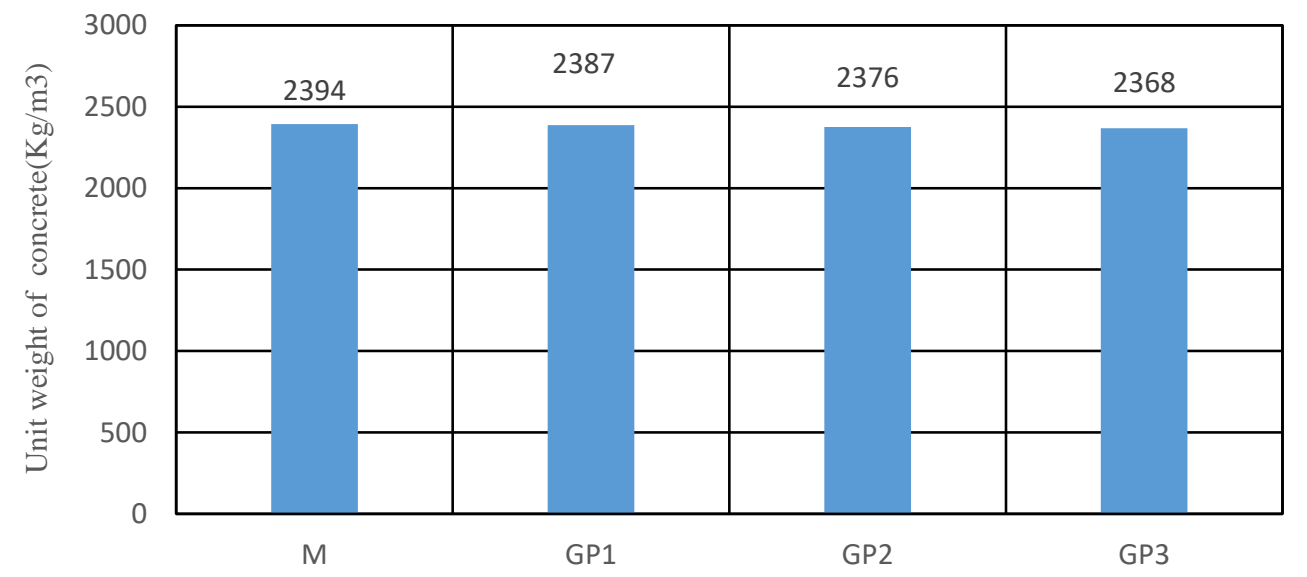

Fig. 6. Density of waste glass powder. 


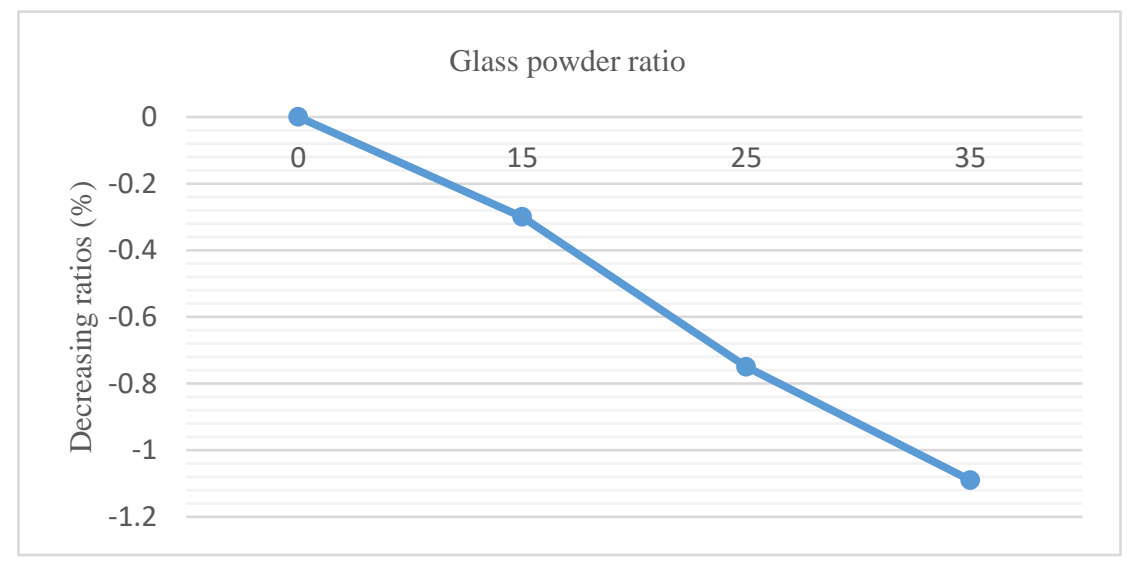

Fig. 7. Decreasing ratios in the density.

\subsection{Compressive strength test}

In this study compressive strength is collected at 7 and 28 days and figure 4 presented the value of compressive strengths of the waste glass mixture. Figure 8 exhibits the increased ratio that occurred in compressive strength. The highest value of the compressive strength test occurred at 28 days was $42.82 \mathrm{Mpa}$ for concrete mix made of $25 \%$ waste glass as sand, which considered an improvement in the strength of about $8 \%$ as compared with the reference mixture. Nevertheless, the mix concrete that contained waste glass above $25 \%$ recorded a low compressive strength than those of the conventional mix, which could be related to the reduction in the adhesive strength among the surface of the cement paste and the waste glass aggregate. Table 5 represents the results of substitute the coarse aggregate by waste ceramic, it displays that utilizing wastage tile as gravel produces a drop in the strength of concrete. Besides, also this reduction is not considered as a negative influence as compared to the conventional mixture. Further, the reason for reduction could be related to the lack of correlation of aggregate in concrete, and also the smooth surface of aggregates. The highest reported strength of the mixtures that include wastage ceramic tile related to the specimen that contained $10 \%$ as compared with other ceramic tile mixture. On the contrary, the least reported strength belonged to the samples containing $60 \%$ wastage tile.

Table 4. Compressive strength of concrete containing waste glass powder.

\begin{tabular}{llccc}
\hline Sr.No & Designation & $\begin{array}{l}\text { Compressive } \\
\text { strength(Mpa) }\end{array}$ & $\begin{array}{c}\text { Compressive } \\
\text { strength (Mpa) } \\
\text { at 28 days }\end{array}$ \\
\hline & & $7^{\text {th }}$ Days & $28^{\text {th }}$ Days & \\
\hline \multirow{4}{*}{1} & \multirow{4}{*}{ GP0 } & 27.32 & 38.75 & 39.65 \\
& & 26.75 & 40.36 & \\
& & 27.55 & 39.85 & \\
\hline \multirow{2}{*}{2} & \multirow{2}{*}{ GP15 } & 27.72 & 41.98 & \\
& & 26.92 & 39.96 & 41.28 \\
& & 28.15 & 41.92 & \\
3 & \multirow{3}{*}{ GP25 } & 27.99 & 43.65 & \\
& & 28.54 & 42.85 & 42.82 \\
& & 28.87 & 41.97 & \\
4 & \multirow{2}{*}{ GP35 } & 25.16 & 37.04 & \\
& & 24.55 & 35.97 & 36.56 \\
& & 24.21 & 36.67 & \\
\hline
\end{tabular}




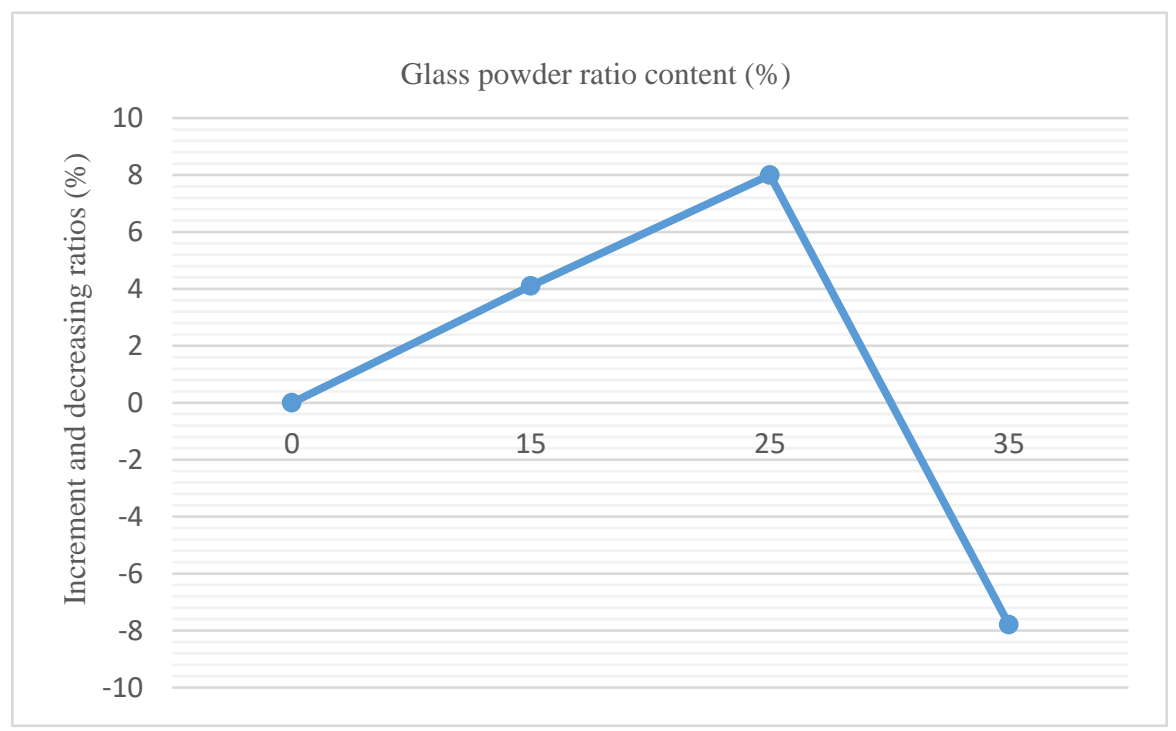

Fig. 8. Increment and decreasing ratios in compressive strength.

Table 5.Compressive strength of concrete containing waste ceramic tile.

\begin{tabular}{|c|c|c|c|c|}
\hline \multirow[t]{2}{*}{ Sr.No } & \multirow[t]{2}{*}{ Designation } & \multicolumn{2}{|c|}{$\begin{array}{l}\text { Compressive strength } \\
\text { (Mpa) }\end{array}$} & \multirow{2}{*}{$\begin{array}{l}\text { Compressive } \\
\text { strength (Mpa) } \\
\text { at } 28 \text { days }\end{array}$} \\
\hline & & $7^{\text {th }}$ Days & $28^{\text {th }}$ Days & \\
\hline \multirow{3}{*}{1} & \multirow{3}{*}{ СТ0 } & 27.32 & 38.75 & \multirow{3}{*}{39.65} \\
\hline & & 26.75 & 40.36 & \\
\hline & & 27.55 & 39.85 & \\
\hline \multirow{3}{*}{2} & \multirow{3}{*}{ CT15 } & 27.12 & 40.46 & \multirow{3}{*}{40.71} \\
\hline & & 26.19 & 41.54 & \\
\hline & & 27.45 & 40.12 & \\
\hline \multirow{3}{*}{3} & \multirow{3}{*}{ СТ30 } & 25.49 & 38.81 & \multirow{3}{*}{38.22} \\
\hline & & 26.14 & 37.82 & \\
\hline & & 24.67 & 38.02 & \\
\hline \multirow{3}{*}{4} & \multirow{3}{*}{ CT45 } & 24.01 & 35.69 & \multirow{3}{*}{35.36} \\
\hline & & 23.65 & 34.95 & \\
\hline & & 24.27 & 35.44 & \\
\hline \multirow{3}{*}{5} & \multirow{3}{*}{ СТ60 } & 22.46 & 32.02 & \multirow{3}{*}{31.47} \\
\hline & & 23.85 & 31.68 & \\
\hline & & 23.29 & 30.73 & \\
\hline
\end{tabular}




\subsection{Split tensile strength test}

The value of tensile strength for the mixtures that contain waste ceramic tiles were found to be slightly higher about $0.72 \%$ at $15 \%$ as resembled the reference mixture. But, at all level replacement of waste tile concrete mixes demonstrated a reduction than those of the conventional samples. Regarding the use of waste glass powder, the result revealed an increment in the amount of split tensile especially at a mixture that included $25 \%$ of waste glass. The outcomes of the split tensile strength test are displayed in figure 9,10 for the two waste ceramic tile and glass powder, respectively.

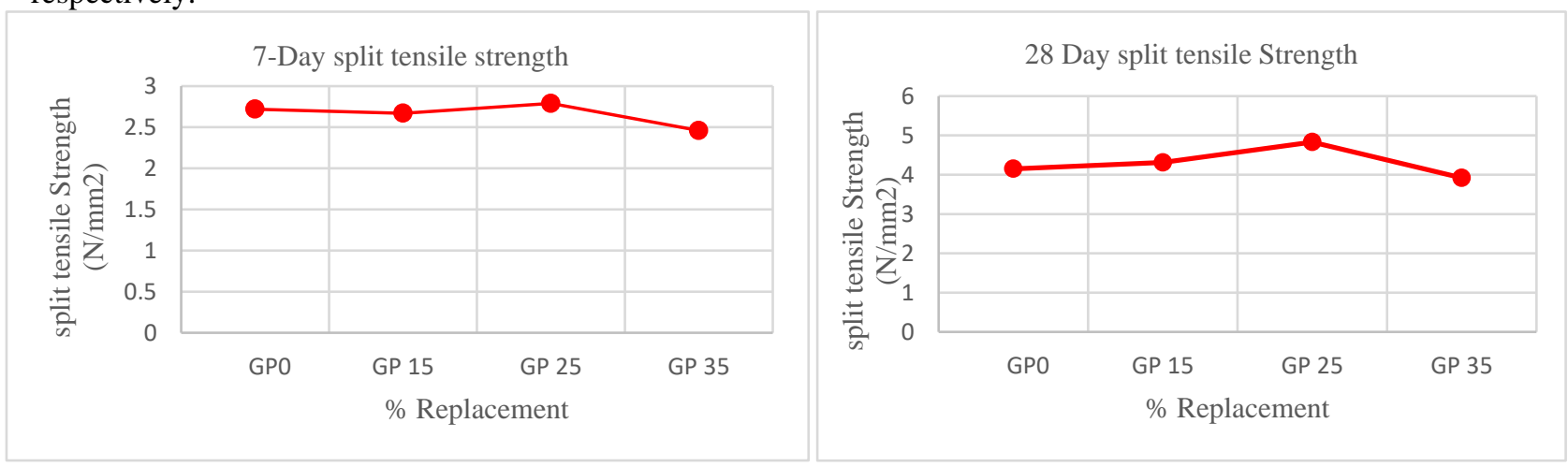

Fig. 9. Split tensile strength of waste glass powder for 7, 28 days.

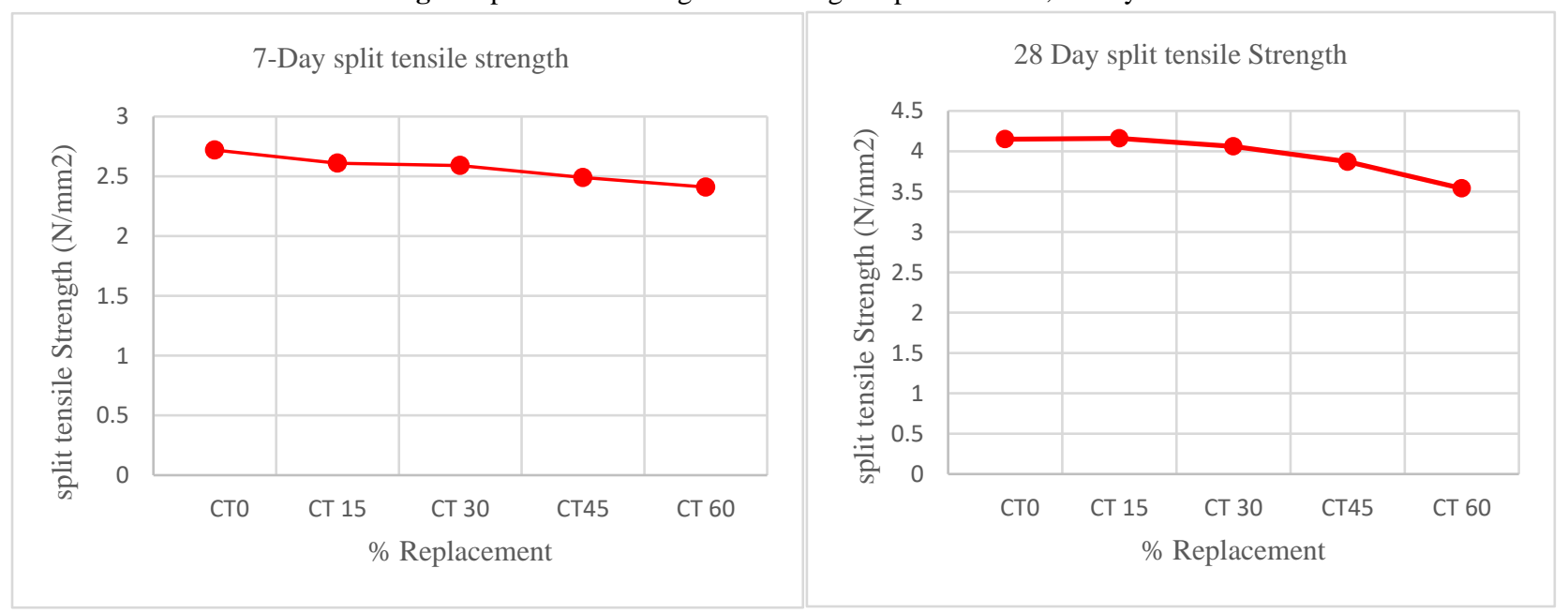

Fig. 10. Split tensile strength of waste ceramic tile for 7,28 days.

\subsection{Flexural strength test}

Figure 11 represented the results of waste glass and ceramic tile in terms of flexural strength test. Generally, the flexural strength of the concrete that includes waste glass powder revealed to be increased as the ratio of glass powder increased. By following the results, at 28-day the value of the flexural strength was recognized to have a great increment above the conventional mix by $7.5 \%$ and $11.8 \%$ as the glass powder content increased by $15 \%$ and $25 \%$, respectively. However, as is evident in the chart while increasing the percentage by more than $25 \%$, a decrease observed in the flexural strength. By utilizing waste ceramic, it found that the amount of flexural strength decreases at all level replacement. Lowest flexural strength witnessed at $60 \%$ substituted waste tiles as aggregate, which represents a reduction of about $13.01 \%$ as make a comparison with the plain mix. 


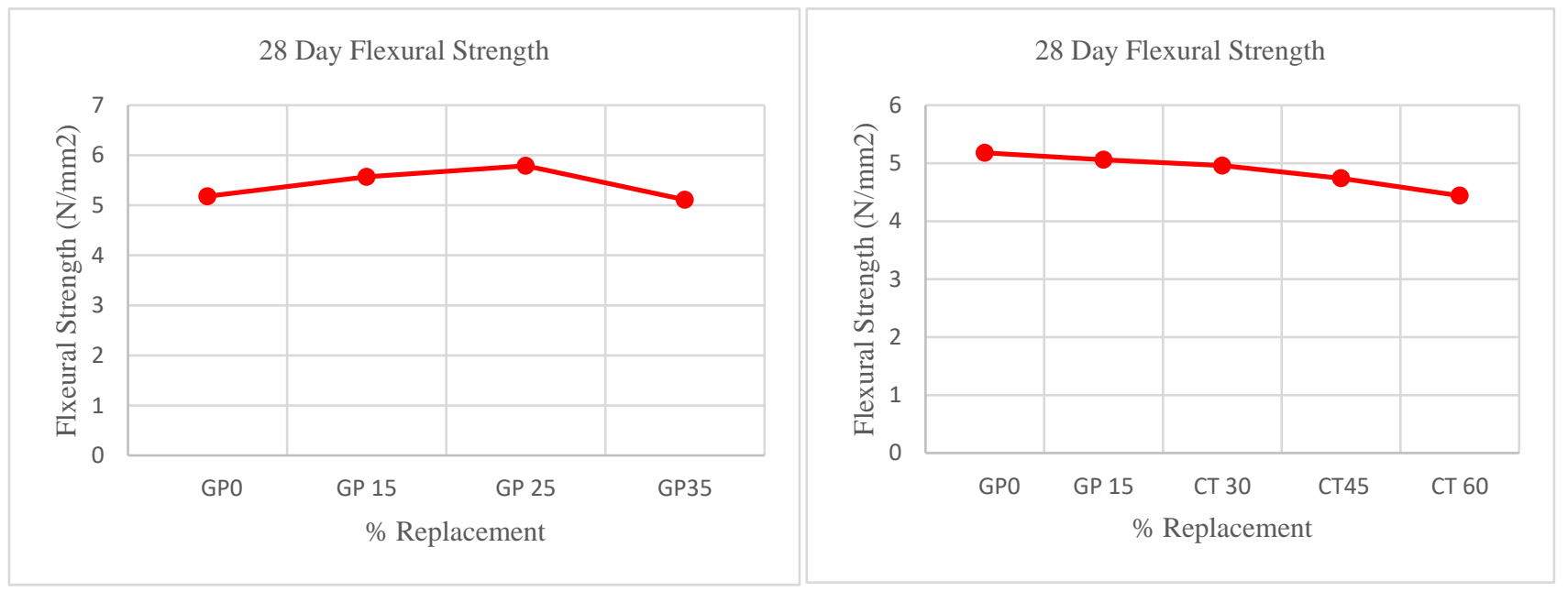

Fig.11. Flexural strength of waste glass powder and waste ceramic for 28 day.

\subsection{RC beam test}

Figure 12 displayed the first crack and ultimate load for the concrete mix that includes waste glass powder. As a result, it appears that by increasing the proportion of waste glass the value of ultimate load has been increased and also delayed the appearance of cracks. Regarding the concrete that content waste ceramic tile it revealed the amount of ultimate load diminished as the rate of waste ceramic increased and the first crack evidence so early as compared to the traditional concrete. Figure 13 showed the first crack and ultimate load of concrete containing waste ceramic tile.

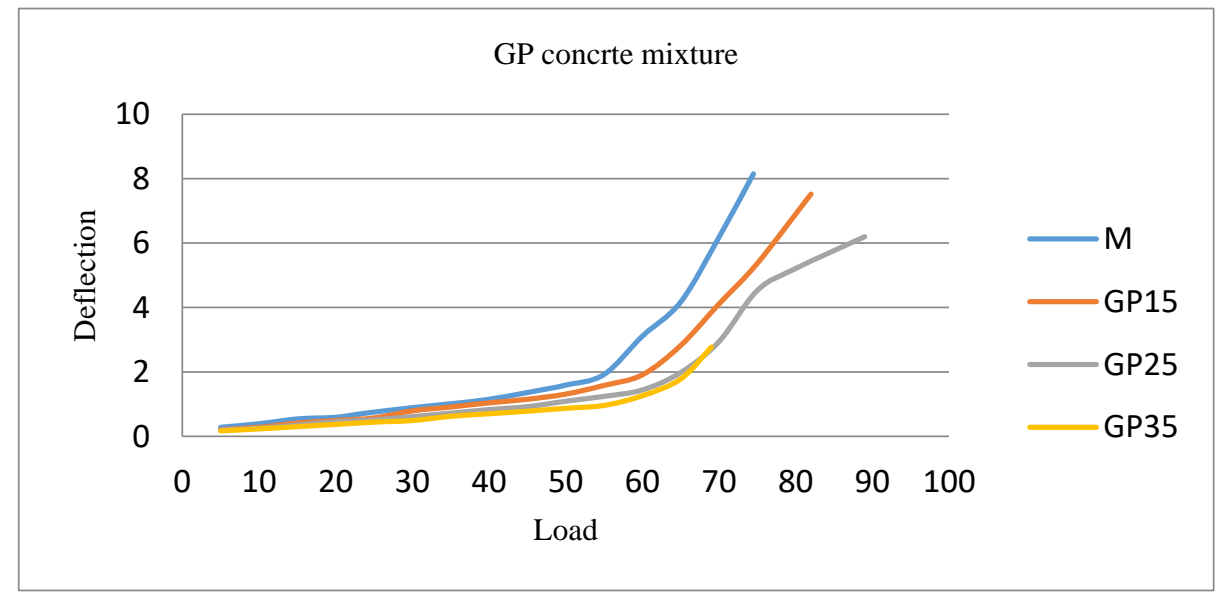

Fig.12. Ultimate load and first crack of concrete containing glass powder. 


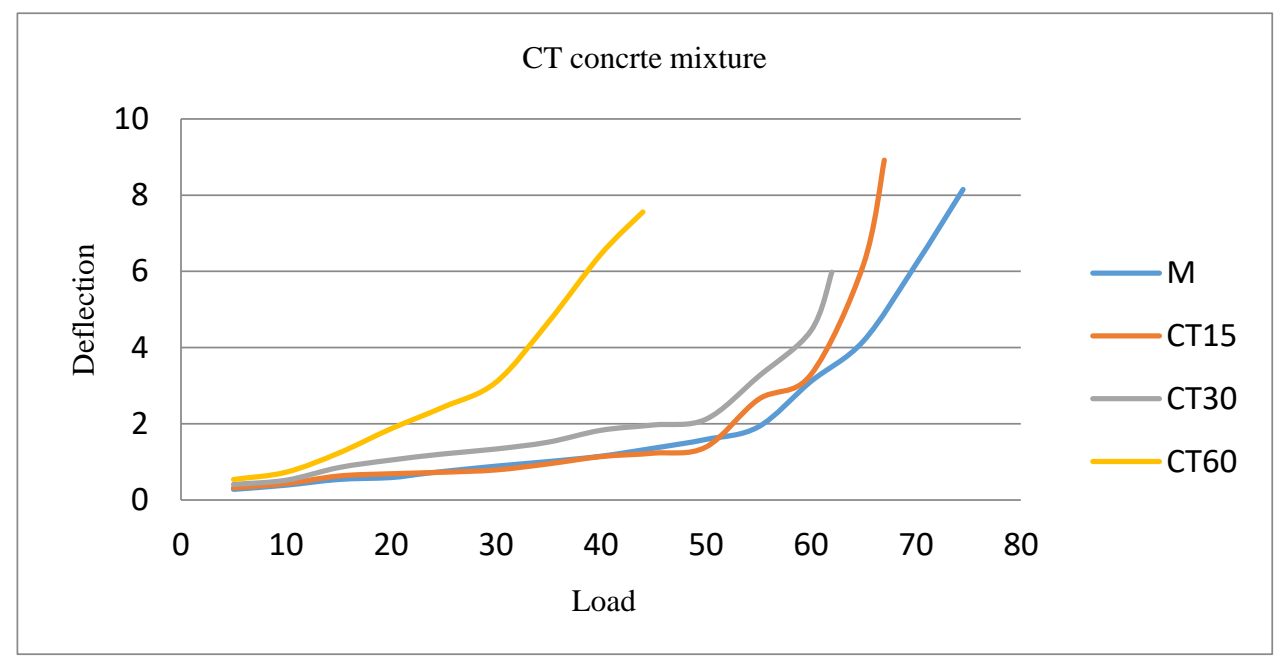

Fig. 13. Ultimate load and first crack of concrete containing waste ceramic.

\subsection{Effect of the combination of GP and CT}

Table 5 displays the result of the combination of concrete in terms of compressive strength. The outcome that collects from the study, showed by incorporating $25 \%$ of GP in the mixture of CT15, CT30, the strength properties have been developed, the enhancement in strength of the mixture of CT15 and CT30 was about $1.8 \%, 3.04 \%$, respectively. As a result, those two wastage materials are considered to be compatible materials in the mixture. Regarding the test of split tensile strength, the concrete that prepared with GP25 and CT15 consider as the highest tensile strength as compared to the conventional mixture and GP25CT30 mixture and the consequences are presented in table 6. At the same amount of GP and CT the test for flexural strength and RC beam tests were performed, it revealed development in strength while utilizing the waste glass in the ceramic tile concrete. Table 5 manifested the results of the test related to flexural strength and the first crack and ultimate load. Figure 14 displayed the first crack and ultimate load of concrete that combined the two waste materials at the same proportion of waste glass powder and ceramic tile.

Table 6. Combination results of waste glass and wastage ceramic tile in concrete.

\begin{tabular}{|c|c|c|c|c|c|c|}
\hline \multirow[t]{2}{*}{ Sample } & \multicolumn{2}{|c|}{$\begin{array}{l}\text { Compressive } \\
\text { strength(Mpa) }\end{array}$} & $\begin{array}{l}\text { Average of } 28 \\
\text { days } \\
\text { compressive } \\
\text { strength (Mpa). }\end{array}$ & \multicolumn{2}{|c|}{$\begin{array}{l}\text { Tensile } \\
\text { strength (Mpa) }\end{array}$} & $\begin{array}{c}\text { Flexural } \\
\text { strength } \\
\text { (Mpa) } \\
28 \text { days }\end{array}$ \\
\hline & 7 Days & 28 Days & & 7 Days & Days & \\
\hline GP25CT15 & $\begin{array}{l}27.82 \\
28.24 \\
28.34\end{array}$ & $\begin{array}{l}40.92 \\
41.72 \\
41.68\end{array}$ & 41.44 & 2.71 & 4.32 & 5.29 \\
\hline GP25CT30 & $\begin{array}{l}25.52 \\
24.86 \\
25.31\end{array}$ & $\begin{array}{l}39.02 \\
40.14 \\
38.78\end{array}$ & 38.38 & 2.62 & 4.14 & 5.14 \\
\hline
\end{tabular}




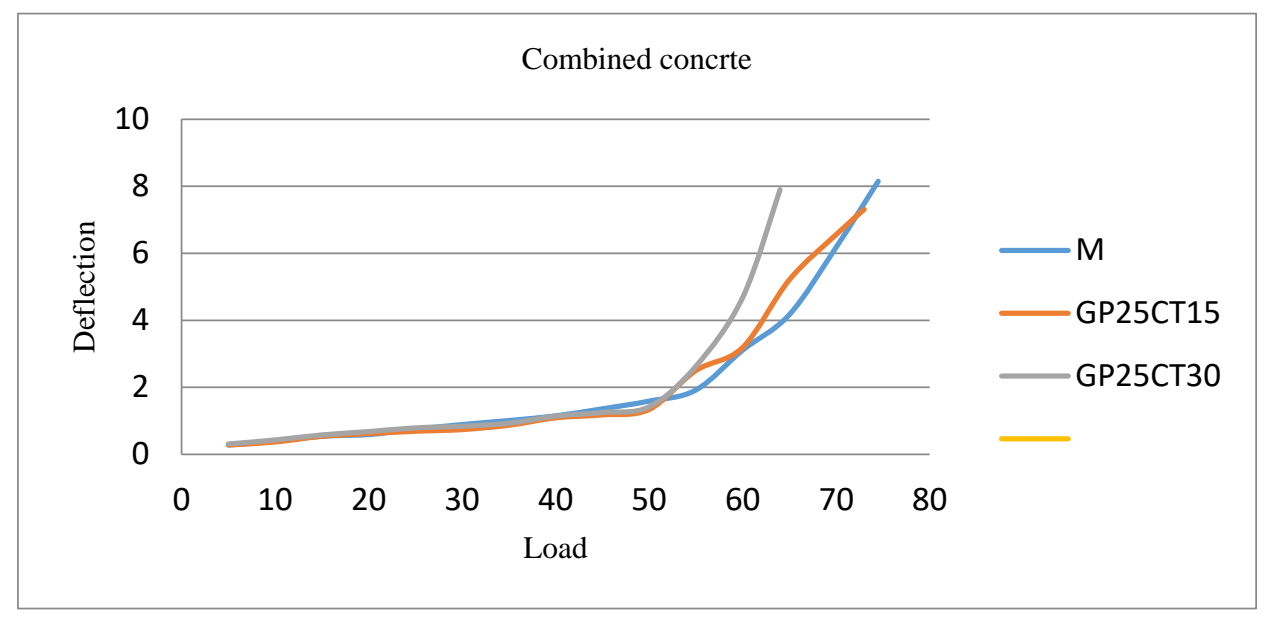

Fig. 14.Ultimate load and first crack of combined concrete.

\subsection{Conclusions}

According to the results that obtained from this study the following main conclusions were derived:

- The value of the slump test has decreased in the concrete mixture that includes waste glass as the percentage of glass powder increased. Even there was a drop in the value of slump for these mixtures, they have suitable workability. Regarding the other mixture that content waste ceramic tile as increased the ratio of ceramic tile the slump value has decreased.

- Using glass powder as a partial substituted for fine aggregate increased the strength characteristics. The perfect percentage of glass powder in the concrete mixture that provides the maximum amounts in terms of the strength characteristics is $25 \%$ of glass waste powder.

- As introduce wastage tile in concrete production it record as no remarkable negative impact on the characteristics of concrete. The optimal mix of incorporated ceramic tile is considered to be among 15 to 30 percent. In these recognizes, not only a suitable strength have been registered, but also a decrease in unit weight.

- The dry densities value of waste glass concrete mixtures showed a slight decline as compared to the conventional mixture.

- By using the waste glass as aggregate it revealed that the first crack has been delayed as compared to the plain mixture and the value of the ultimate load has been increased. However, ceramic tile as aggregate reduces the ultimate load and the first crack appears early as compared with the plain mix.

- Using tile wastage and glass powder in concrete leads to the removal of those materials from the environment. Besides, decreasing the utilization of raw materials, also these wastage materials are considered as positive economically. 


\section{REFERENCES}

[1] Rakshvir, M., Barai, S.V.: Studies on recycled aggregates-based concrete. Waste Management \& Research.Vol.24, No.3, pp.225-233 (2006)

[2] Yong, P. C. and Teo, D. C. L.: Utilisation of recycled aggregate as coarse aggregate in concrete. Journal of Civil Engineering Science and Technology.Vol.1, No.1, pp.1-6(2009)

[3] N.A. Soliman, A. Tagnit-Hamou.: Development of ultra-high-performance concrete using glass powder towards eco-friendly concrete. Constr. Build. Mater. Vol.125, pp.600-612 (2016)

[4] Torgal F, Jalali S.: Compressive strength and durability properties of ceramic wastes based concrete. Construction and Building Materials. Vol.24, pp.832-8 (2010)

[5] A. Shayan, A. Xu.: Performance of glass powder as a pozzolanic material in concrete: a field trial on concrete slabs. Cement and Concrete Research. Vol.36, No.3, pp.457-468 (2006)

[6] H. Du, K.H. Tan.: Waste glass powder as cement replacement in concrete. J. Adv. Concr. Technol. Vol.12, No.11, pp.468-477 (2014)

[7] G. Lee, C.S. Poon, Y.L. Wong, T.C. Ling.: Effects of recycled fine glass aggregates on the properties of dry-mixed concrete blocks. Constr. Build. Mater. Vol.38, pp.638-643 (2013)

[8] H. Zhao, C.S. Poon, T.C. Ling.: Utilizing recycled cathode ray tube funnel glass sand as river sand replacement in the high-density concrete. J. Clean. Prod.Vol.51, pp.184-190 (2013)

[9] T.C. Ling, C.S. Poon.: Use of recycled CRT funnel glass as fine aggregate in dry mixed concrete paving blocks, J. Clean. Prod.Vol.68, pp.209-215 (2014)

[10] T.C. Ling, C.S. Poon.: Properties of architectural mortar prepared with recycled glass with different particle sizes. Mater. Des.Vol.32, No.5, pp.2675-2684 (2011)

[11] S.B. Park, B.C. Lee, J.H. Kim.: Studies on mechanical properties of concrete containing waste glass aggregate. Cement and Concrete Research.Vol.34, No.12, pp.2181-2189 (2004)

[12] I.B. Topçu, M. Canbaz.: Properties of concrete containing waste glass. Cem. Concr. Res. Vol.34, No.2, pp.267274 (2004)

[13] S.C. Kou, C.S. Poon.: Properties of self-compacting concrete prepared with recycled glass aggregate. Cement \& Concrete Composites.Vol.31, pp.107-113 (2009)

[14] S. Multon, M. Cyr, A. Sellier, N. Leklou, L. Petit.: Coupled effects of aggregate size and alkali content on ASR expansion. Cement and Concrete Research.Vol.38, pp.350-359 (2008)

[15] Thomas.M: The effect of supplementary cementing materials on alkali-silica reaction. Cement and Concrete Research.Vol.41, pp.1224-1231(2011)

[16] Idir.R, Cyr.M, Tagnit-Hamou.A.: Use of fine glass as ASR inhibitor in glass aggregate mortars. Construction and Building Materials.Vol.24, pp.1309-1312 (2010)

[17] Cota.F.P, Melo.C.C.D, Panzera.T.H, Araújo.A.G, Borges.P.H.R, Scarpa.F. Mechanical properties and ASR evaluation of concrete tiles with waste glass aggregate. Sustainable Cities and Society (2015)

[18] Saccani.A, Bignozzi.M.C.: ASR expansion behavior of recycled glass fine aggregates in concrete. Cement and Concrete Research.Vol.40, pp.531-536 (2010) 